\title{
Reducing Energy Consumption and Increasing the Performances of AC Motor Drives Using Fuzzy PI Speed Controllers
}

\author{
Constantin Volosencu (D)
}

check for updates

Citation: Volosencu, C. Reducing Energy Consumption and Increasing the Performances of AC Motor Drives Using Fuzzy PI Speed Controllers. Energies 2021, 14, 2083. https:// doi.org/10.3390/en14082083

Academic Editors: Kyeong-Hwa Kim and Anastasios Dounis

Received: 2 March 2021

Accepted: 7 April 2021

Published: 8 April 2021

Publisher's Note: MDPI stays neutral with regard to jurisdictional claims in published maps and institutional affiliations.

Copyright: (C) 2021 by the author. Licensee MDPI, Basel, Switzerland. This article is an open access article distributed under the terms and conditions of the Creative Commons Attribution (CC BY) license (https:/ / creativecommons.org/licenses/by/ $4.0 /)$.
Department of Automation and Applied Informatics, Faculty of Automation and Computers, Politehnica University Timisoara, 300006 Timisoara, Romania; constantin.volosencu@aut.upt.ro; Tel.: +40-25-640-3239

\begin{abstract}
Alternating current electric drives are widely used in many commercial applications. Increasing energy efficiency and improving the quality of regulation are major goals. The speed control structure of the induction machine with indirect vector control with rotor flux orientation and the speed control structure of the permanent magnet synchronous machine with vector control with rotor flux orientation are taken into account. The control structures were modeled and simulated in Simulink. Different simulation regimes were made for different load torques and different parameters. Following the analyses performed, it was highlighted that the fuzzy regulation ensures the reduction of the energy consumption in transient states and the improvement in the quality indicators of the regulation. The fuzzy control systems are robust to the errors of identification of the machine parameters and to the effect of the disturbing load torque.
\end{abstract}

Keywords: AC drives; induction motors; permanent magnet synchronous motors; brushless motors; fuzzy PI controllers; digital control of AC drives; nonlinear control; robust control

\section{Introduction}

Reducing energy consumption throughout the operation of an electric drive is an important goal in the design of automatic control structures for electric machines. The use of fuzzy PI regulators in the control of electric drives is a feasible solution that ensures the reduction in electricity consumption and the improvement of regulation performances. In recent years, numerous papers have appeared in the literature dealing with the use of fuzzy PI regulators in such applications.

From the specialized literature, we can mention some works such as an application on smart energy management based on a control scheme, which integrates a fuzzy logic controller within a voltage-oriented control strategy, implemented, and simulated in Simulink [1]; a systematic categorization of multi-motor techniques with a review of fuzzy logic controllers and their functionalities in multi-motor control [2]; and an application of a reversible three-phase PWM converter in a wide range of $A C$ voltage and DC voltage drives by using a double fuzzy PI controller [3]. The development of a power supply control system based on fuzzy logic for an electric vehicle, in order to minimize the total energy consumption and optimize the battery operation, is presented in [4]. The paper shows improvements in some dynamics such as overshoot, settling time, and steady-state error parameters. It is shown that this fuzzy controller increases the overall energy efficiency of the vehicle. A type-2 fuzzy logic controller as the speed controller, acting as the driver model controller in autonomous electric vehicles, is presented in [5] as an alternative to save energy and to preserve the performances. Several other recently published papers dealing with the problems of fuzzy control of electric drives may be mentioned, as follows. A type 1 Mamdani fuzzy logic controller for electric vehicle drive is discussed in [6]. A real time adaptive speed control system of vector controlled induction motor drive based on online trained type 2 fuzzy neural network controller is presented in [7]. The role of 
optimization algorithms based on fuzzy controller in achieving induction motoir performance enhancement is analyzed in [8]. An experimental setup for implementation of fuzzy logic control for indirect vector-controlled induction motor drives is presented is presented in [9].

The technology of control electric drives has been developed based on new control methods such as fuzzy logic, field-oriented regulation theory, and digital equipment based on advanced microprocessors. The problem of intelligent control of electric drives has been addressed in numerous papers over the years including the application of expert systems, fuzzy logic, and neural networks in electric drives [10]; fuzzy control of switched reluctance motor drives [11]; or fuzzy adaptive vector control of induction motor drives [12]. The control structure of AC drives were developed based on the basic theory and principles from the literature as follows. The induction motors and the permanent magnet synchronous motors are the main actuators in industrial and commercial use, which offer energy savings and system optimization, and their control structures were developed using the principles presented in [13-16]. The modeling and simulation of electric drive control systems were made based on the principles presented in [17]. The development of the fuzzy PI controllers was made based on the theoretical bases of the design of fuzzy PID controllers presented in [18]. The author has researched the field of fuzzy control of electric drives and has published works in the literature, as follows. Fuzzy control systems for DC drives and permanent magnet synchronous are presented in [19] and respectively in [20]. The demonstration of the robustness of fuzzy control systems is presented in [21]. Methods of designing PI fuzzy controllers based on a pseudo-equivalence with linear controllers are presented in [22-24]. A method to assure the stability of fuzzy control systems based on fuzzy PI controllers is presented in [25]. Additionally, some properties of fuzzy systems useful in control systems are presented in [26-28].

The paper presents a consideration of two digital fuzzy control structures of the two main AC machines used in practice: induction motors and permanent magnet synchronous motors. For each control system, the transient state characteristics obtained by simulation with Simulink are presented. Three types of load torques, common in practice, are considered. Transient state analyses are performed for nominal values of the machine parameters as well as in the case in which the machine parameters suffer a deviation of $100 \%$ from the nominal values. Based on the transient state characteristics, the values obtained for the performance indicators of the control systems can be highlighted such as overshoot, rise time, error, and others. A practical experiment conducted with a speed control system of a permanent magnet synchronous motor with a Hall sensor encoder, fed by a three phase inverter, based on a signal processor, demonstrated that by using fuzzy PI controllers, some performance indicators may be improved, obtaining a shorter rise time and a zero overshoot. An example of the calculation of the reduction in energy consumption is presented. The novelty of the paper is a synthetic analysis performed on the main alternating current machines by modeling and simulation, for nominal values and with deviations of the machine parameters, for three different types of load torques, resulting in 24 cases of analysis, with each case calculating the performance indicators of the regulation, demonstrating for each case that using fuzzy PI controllers obtains a reduction of the consumed energy, the improvement of the performance indicators, and the robustness of the control system.

\section{Control Structures}

\subsection{Induction Motor}

The block diagram of the fuzzy speed control structure for induction motors is presented in Figure 1. 


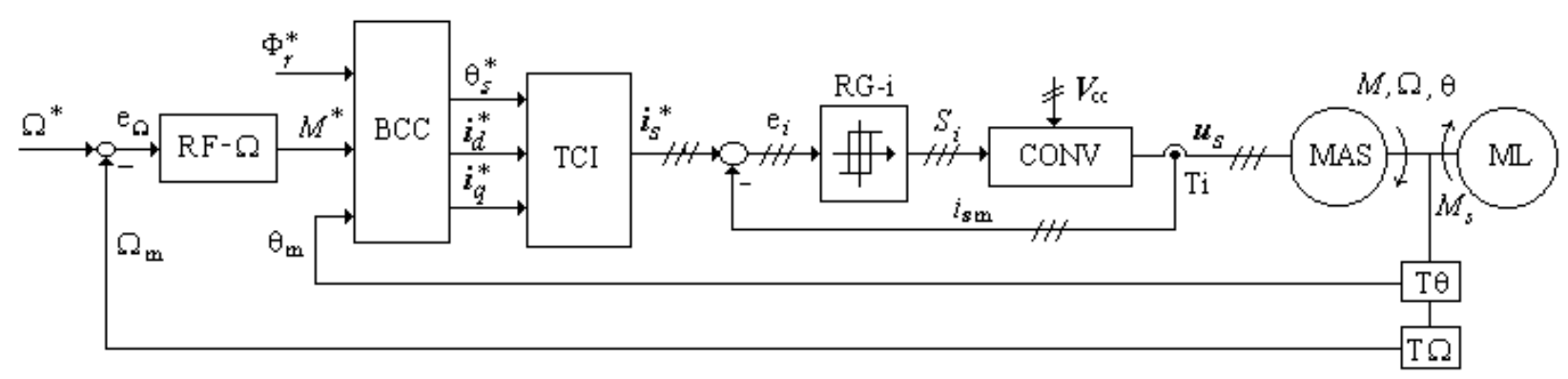

Figure 1. Block diagram of the three-phase asynchronous machine speed control system with fuzzy speed controller.

The meanings of the notations in the Figure 1 are as follows: MAS-induction machine; ML-working machine; CONV-power electronic convertor; RG-i-stator phase current controllers; Ti-current sensor; $\mathrm{T} \theta$-position sensor; $\mathrm{T} \Omega$ - speed sensor; TCI-inverse Park coordinate transformation [14]; BCC - block for calculating the reference currents in the vector control structure of the asynchronous machine with rotor flux orientation [14,29]; RF$\Omega$-speed fuzzy PI controller; $\Omega$-rotor speed; $\Omega^{*}$-speed reference; $M^{*}$-torque reference; $\phi_{\mathrm{r}}{ }^{*}$-rotor flux reference; $\theta_{\mathrm{s}}{ }^{*}$-stator phasor position reference; $i_{\mathrm{d}}{ }^{*}, i_{\mathrm{q}}{ }^{*}-\mathrm{d}$, q stator current references; $i_{\mathrm{s}}{ }^{*}$-stator current reference; $\Omega_{\mathrm{m}}$-measured speed; $\theta_{\mathrm{m}}$-measured rotor position; $i_{\mathrm{sm}}$-measured stator currents; $e_{\Omega}$-speed error; $e_{\mathrm{i}}$-current error; $S_{\mathrm{i}}$-control signals for power converter switches with pulse width modulation; $V_{\text {cc }}-$ DC converter supply voltage; $u_{\mathrm{s}}$-stator voltages; $M_{\mathrm{s}}$-load torque. The induction motor is vector controlled with rotor flux orientation, with rotor flux reference $\phi^{*}$ and torque reference $M^{*}$ and the measured rotor position $\theta_{\mathrm{m}}$. The reference stator currents are calculated with the block TCI. The current regulators RG-i give the pulse width modulation signals $S_{\mathrm{i}}$ for the electronic power convertor $\mathrm{CONV}$, fed from a DC voltage source $V_{\mathrm{CC}}$. The power converter CONV gives the stator voltages $u_{\mathrm{s}}$.

The mathematical model of the induction machine $[14,29,30]$ is given by Equation (1) for a general flux orientation, where in the case or rotor orientation $\theta_{\mathrm{f}}=\theta_{\mathrm{r}}$.

$$
\begin{gathered}
\underline{u}_{s f}=\underline{u}_{s} e^{-j \theta_{f}}, \underline{i}_{s f}=\underline{i}_{s} e^{-j \theta_{f}}, \underline{\Phi}_{s f}=\underline{\Phi}_{s} e^{-j \theta_{f}}, \underline{u}_{r f}=\underline{u}_{r} e^{-j \theta_{f}+\theta}, \underline{i}_{r f}=\underline{i}_{r} e^{-j \theta_{f}+\theta}, \\
\underline{\Phi}_{r f}=\underline{\Phi}_{r} e^{-j \theta_{f}+\theta}, \underline{u}_{s f}=R_{s} \underline{i}_{s f}+\frac{d \underline{\Phi}_{s f}}{d t}+j \omega_{f} \underline{\Phi}_{s f}, \underline{u}_{r f}=R_{r} \underline{i}_{r f}+\frac{d \underline{\Phi}_{r f}}{d t}+j\left(\omega_{f}-\omega\right) \underline{\Phi}_{r f}, \\
M=\frac{3}{2} n_{p} L_{m} \operatorname{Re}\left\{j \underline{i}_{s f} \cdot \underline{i}_{r f}^{*}\right\}, J \frac{d \Omega}{d t}=M-k_{f} \Omega-M_{s}
\end{gathered}
$$

The other notations in Equation (1) have the following meanings: $u_{\mathrm{s} f}, i_{\mathrm{sf}}, \Phi_{\mathrm{sf}}$-stator voltage, current, and flux, respectively, where the notation $\mathrm{f}$ means with general flux orientation; $u_{\mathrm{rf}}, i_{\mathrm{rf}}, \Phi_{\mathrm{rf}}$-rotor voltage, current, and flux, respectively; $R_{\mathrm{s}}$-rotor resistance; $L_{\mathrm{m}}$-magnetic flux inductance; $\omega$-rotor frequency; $\omega_{\mathrm{f}}$-stator frequency; $J$-motor inertia; $k_{\mathrm{f}}$-friction coefficient.

The block for calculating the reference currents in the vector control structure of the asynchronous machine with rotor flux orientation BCC has the block diagram from Figure $2 \mathrm{a}[14,29,31]$. where the block $\mathrm{CC}$ has the structure from Figure $2 \mathrm{~b}$ and the general magnetic flux $\phi_{\mathrm{m}}{ }^{\mathrm{c} *}$ is the rotor flux $\Phi_{\mathrm{r}}{ }^{*} ; n_{\mathrm{p}}$-is the pole pair number; $L_{\mathrm{m}, \mathrm{r}}$-magnetic and rotor inductances; $s-$ slip frequency; $R_{\mathrm{r}}$-rotor resistance; $\omega_{\mathrm{s}}{ }^{*}$-stator frequency reference. 


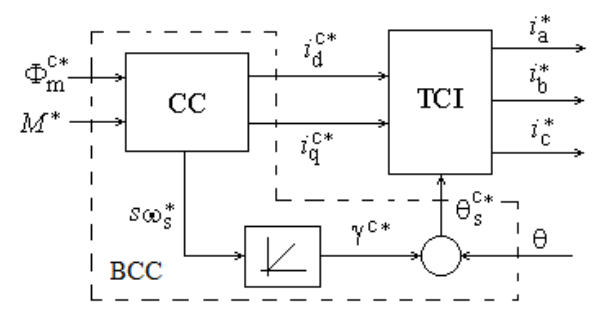

(a)

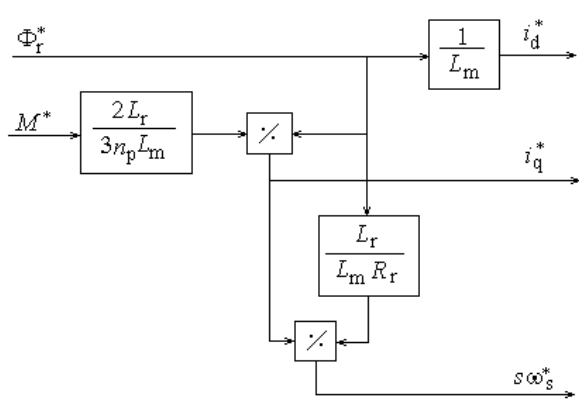

(b)

Figure 2. (a,b) The structure of the block for calculating the reference currents in the vector control structure of the asynchronous machine with rotor flux orientation (BCC).

Two-position current regulators RG-i with hysteresis were used, considering an unfavorable regulation case.

Calculation values of the induction motor were: $\mathrm{R}_{\mathrm{s}}=12.4 \Omega ; \mathrm{R}_{\mathrm{r}}=124 \Omega ; \mathrm{L}_{\mathrm{m}}=0.8 \mathrm{H}$; $\mathrm{L}_{\mathrm{s} \sigma}=0.06 \mathrm{H} ; \mathrm{L}_{\mathrm{r} \sigma}=0.06 \mathrm{H} ; p=4 ; \mathrm{k}_{\mathrm{f}}=0.008 \mathrm{Nms} ; \mathrm{J}=0.01 \mathrm{kgm}^{2} ; \mathrm{M}_{\mathrm{Mc}}=7 \mathrm{Nm} ; \mathrm{M}_{\mathrm{Mt}}=24 \mathrm{Nm}$; $\Omega_{\mathrm{b}}=750 \mathrm{rot} / \mathrm{min} ; \mathrm{P}_{\mathrm{N}(\mathrm{Mc})}=550 \mathrm{~W} ; \mathrm{I}_{\mathrm{sN}}=1.77 \mathrm{~A} ; \mathrm{I}_{\mathrm{sM}}=8 \mathrm{~A} ; \mathrm{U}_{\mathrm{sN}}=220 \mathrm{~V}$.

\subsection{Permanent Magnet Synchronous Motor}

The block diagram of the fuzzy speed control structure for permanent magnet synchronous motor is presented in Figure 3 [20].

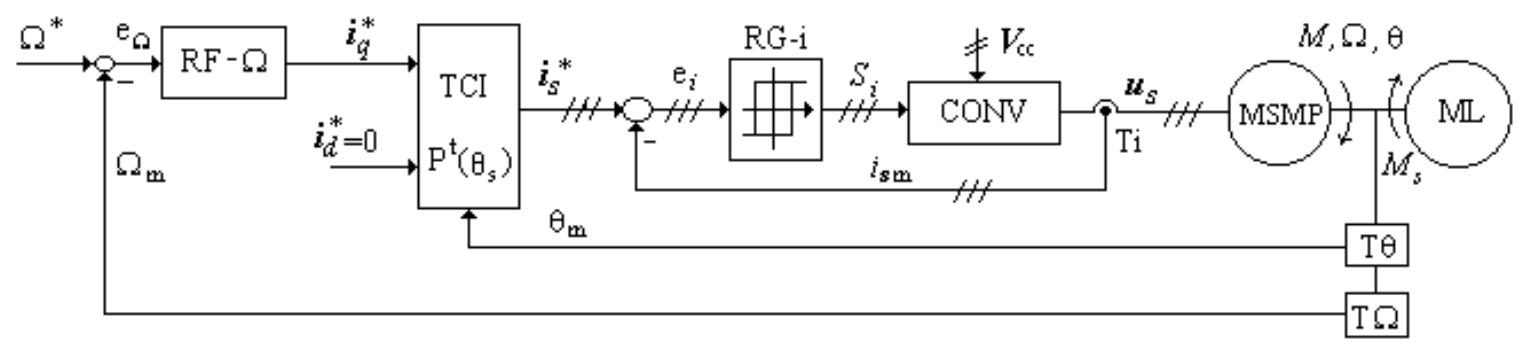

Figure 3. Block diagram of the three-phase permanent magnet synchronous machine speed control system with fuzzy speed controller.

The meanings of the notations in Figure 3 are the same as in Figure 1, and MSMP is the permanent magnet synchronous machine. The permanent magnet synchronous motor is vector controlled with rotor flux orientation $[15,29,30]$ with rotor $\mathrm{q}$ current $i_{\mathrm{q}}^{*}$ as a torque reference, the rotor $\mathrm{d}$ current $i_{\mathrm{d}}^{*}$ at zero as a flux reference $\phi^{*}$, and the measured rotor position $\theta_{\mathrm{m}}$.

The mathematical model of the permanent magnet synchronous machine $[15,29,30]$ is given by the Equation (2).

$$
\begin{gathered}
\underline{u}_{s f}=\underline{u}_{s} e^{-j \theta}, \underline{i}_{s f}=\underline{i}_{s} e^{-j \theta}, \underline{\Phi}_{s f}=\underline{\Phi}_{s} e^{-j \theta}, \underline{u}_{s f}=R_{s} \underline{i}_{s f}+\frac{d \underline{\Phi}_{s f}}{d t}+j \omega \underline{\Phi}_{s f}, \\
M=\frac{3}{2} \operatorname{Re}\left\{j \underline{\Phi}_{s f} \cdot \underline{i}_{s f}^{*}\right\}, J \frac{d \Omega}{d t}=M-k_{f} \Omega-M_{s}
\end{gathered}
$$

The notations in Equation (2) are similar to those in Equation (1).

Calculation values of the permanent magnet synchronous motor were: $\mathrm{P}_{\mathrm{N}}=400 \mathrm{~W}$; $\mathrm{I}_{\mathrm{N}}=3 \mathrm{~A} ; \mathrm{I}_{\mathrm{M}}=8 \mathrm{~A} ; \mathrm{n}_{\mathrm{m}}=4000 \mathrm{rot} / \mathrm{min} ; \mathrm{n}_{\mathrm{b}}=3000 \mathrm{rot} / \mathrm{min} ; \mathrm{M}_{\mathrm{Mc}}=1.3 \mathrm{Nm} ; \mathrm{M}_{\mathrm{Mt}}=3.4 \mathrm{Nm} ;$ $\mathrm{J}=0.001 \mathrm{kgm}^{2} ; \mathrm{k}_{\mathrm{f}}=0.0001 \mathrm{Nms} ; \mathrm{R}_{\mathrm{s}}=0.6 \Omega ; \mathrm{L}_{\mathrm{d}}=4 \mathrm{mH} ; \mathrm{L}_{\mathrm{q}}=5 \mathrm{mH} ; \mathrm{p}=4 ; \Phi_{\mathrm{e} 0}=0.072 \mathrm{~Wb}$; $\mathrm{V}_{\mathrm{cC}}=200 \mathrm{~V}$. 


\subsection{Fuzzy PI Controller}

The block diagram of the fuzzy speed controller RF- $\Omega$ is presented in Figure 4.

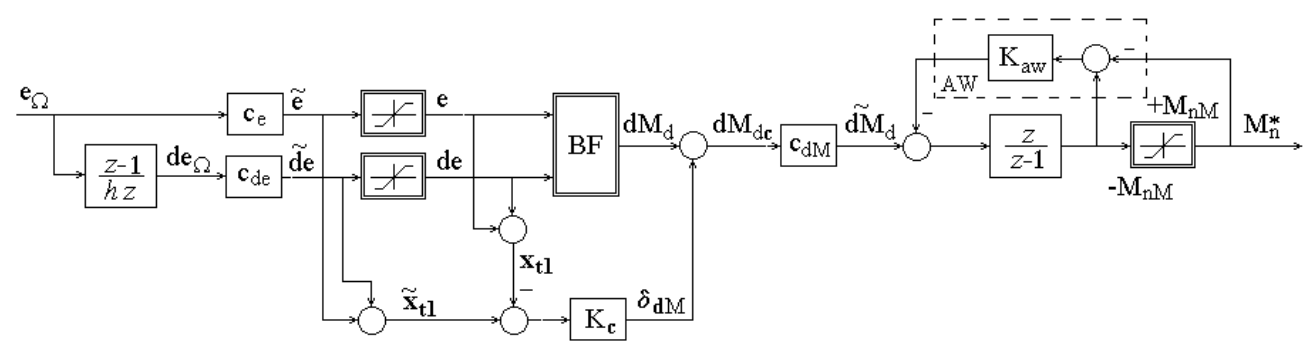

Figure 4. Block diagram of the fuzzy speed controller.

The meanings of the notations in Figure 4 are: $e$-scaled angular speed error; descaled derivative of angular speed error; $d M_{d}$-reference of the derivative of torque $M$; AW-anti-wind-up circuit; $M^{*}$ - torque reference; $c_{\mathrm{e}}, c_{\mathrm{de}}, c_{\mathrm{dM}}$-scaling coefficients; $x_{\mathrm{t} 1}$ compound variable; BF-fuzzy block.

The fuzzy block BF is designed based on the principle of Mamdani, with fuzzification, rule base with nine rules, maxim-minim inference, and defuzzification with center of gravity [18-20]. For the input and output variables, three fuzzy values were chosen: negative, positive $\mathrm{P}$, and zero $\mathrm{Z}$-with the membership functions from Figure $5 \mathrm{a}$. This configuration of fuzzification, inference, and defuzzification gives the highest nonlinear character for the fuzzy block [26-28], useful to improve control performances [19,21].
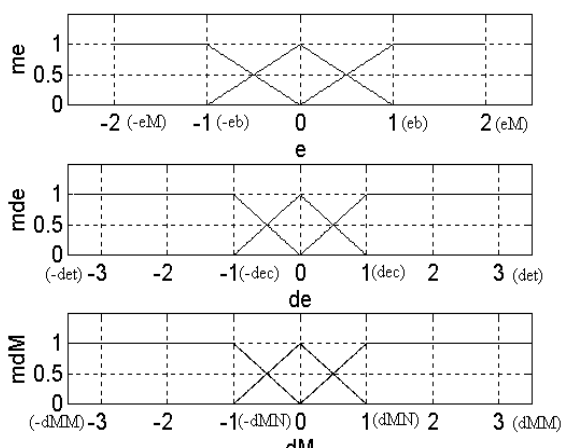

(a)

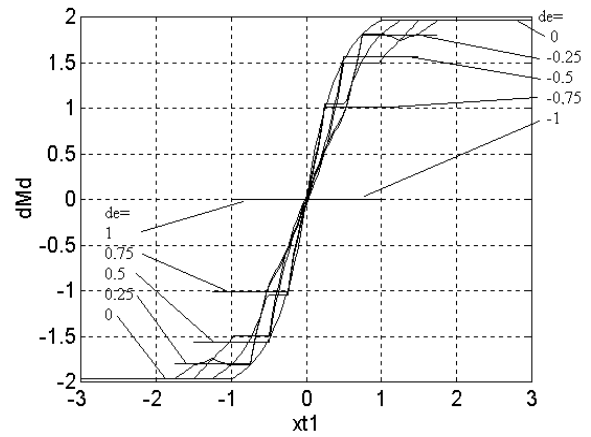

(c)

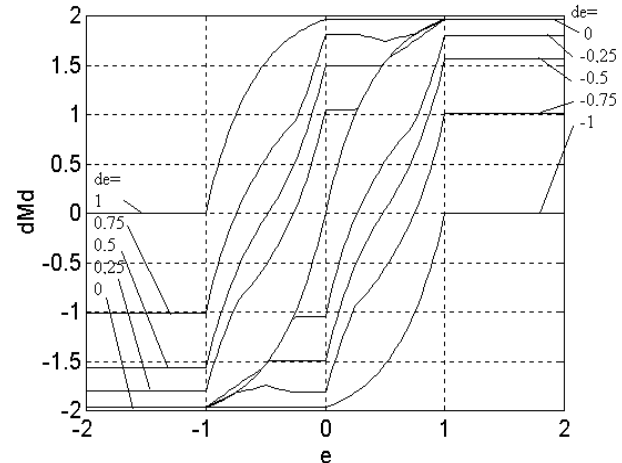

(b)

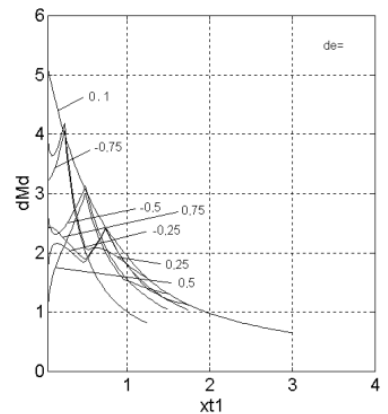

(d)

Figure 5. The transfer characteristics of the fuzzy block BF: (a) membership functions; (b) family of characteristics $f_{\mathrm{e}}(e ; d e)$; (c) family of characteristics $f\left(x_{\mathrm{t} 1} ; d e\right)$; (d) family of characteristics $K_{\mathrm{BF}}\left(x_{\mathrm{t} 1} ; d e\right)$.

The fuzzy block BF may be analyzed based on the transfer characteristics presented in Figure $5[19,22]$. 
The membership functions for the two inputs and one output are presented in Figure 5a. The transfer characteristics $d M_{d}=f_{\mathrm{e}}(e ; d e)$ are presented in Figure $5 \mathrm{~b}$, were $e$ is the variable and $d e$ is the parameter. The characteristics $d M_{d}=f\left(x_{\mathrm{t} 1} ; d e\right)$ are presented in Figure $5 \mathrm{c}$, were $x_{\mathrm{t} 1}$ is a compound variable, given by relation $x_{\mathrm{t} 1}=e+d e$. The gain characteristics $d M_{d}=K_{\mathrm{BF}}\left(x_{\mathrm{t} 1} ; d e\right)$ is given in Figure $5 \mathrm{~d}$.

Figure 5 shows the characteristics of the fuzzy block for the induction machine. Those for the permanent magnet synchronous motor were almost similar.

The design of the fuzzy speed regulator was conducted by a pseudo-equivalence with the linear PI regulator $[19,22-24]$, based on the following reasoning. If the fuzzy block BF is linearized around the permanent regime operating point with $e=0, d e=0$, and $d M_{\mathrm{d}}=0$, a relation of the form (3) is obtained:

$$
d M_{d}=K_{0}(e+d e)
$$

The value $K_{0}$ can be determined with sufficient approximation at the limit on the characteristic families of the fuzzy blocks $K_{\mathrm{BF}}=\left(x_{\mathrm{t} 1} ; d e\right)$, see relation (4).

$$
K_{0}=\lim _{x_{t 1} \rightarrow 0} K_{B F}\left(x_{t 1} ; 0\right)
$$

Taking into account the correction made on the fuzzy block with the torque increment coefficient $c_{\mathrm{dM}}$, the characteristic of the corrected and linearized fuzzy block around the origin is given by the relations:

$$
d \tilde{M}_{d}=c_{d i} K_{0}(e+d e), \tilde{c}_{d i}=c_{d i} K_{0}
$$

For the fuzzy speed controller RF- $\Omega$ with the linearized fuzzy block BF, the following input-output relationship can be written in the $z$ domain:

$$
M_{n}^{*}(z)=\frac{z}{z-1} \tilde{c}_{d i}[e(z)+d e(z)]=\frac{z}{z-1} \tilde{c}_{d i}\left[c_{e}+c_{d e} \frac{z-1}{h z}\right] e_{\Omega}(z)
$$

With these observations, the transfer function of the fuzzy linearized RF- $\Omega$ speed controller becomes:

$$
H_{R F}(z)=\frac{M_{n}^{*}(z)}{e_{\Omega}(z)}=\frac{z}{z-1} \tilde{c}_{d i}\left(c_{e}+c_{d e} \frac{z-1}{h z}\right)
$$

A pseudo-equivalence of the fuzzy speed controller RF- $\Omega$ can be made with a continuous speed controller such as the one chosen for conventional speed control systems:

$$
H_{R \Omega}(s)=K_{R \Omega}\left(1+\frac{1}{s T_{R \Omega}}\right)
$$

For this, the following quasi-continuous form is used:

$$
H_{R F}(s)=\frac{M_{n}^{*}(s)}{e_{\Omega}(s)}=\left.H_{R F}(z)\right|_{z=\frac{1+s h / 2}{1-s h / 2}}=\frac{\tilde{c}_{d i}}{h}\left(c_{d e}+\frac{h}{2} c_{e}\right)\left[1+\frac{c_{e}}{\left(c_{d e}+c_{e} h / 2\right) s}\right]
$$

It is observed that the above transfer function resembles the transfer function (9) of the linear speed PI controller, used in the conventional control structure. The identification of the coefficients of the transfer functions (9) and (10) shows some equalities, and from these equalities are deduced the relations of expression of the scaling coefficients based on the parameters of the already existing speed regulator:

$$
c_{e}=\frac{h K_{R \Omega}}{c_{d M} K_{0} T_{R \Omega}}, c_{d e}=c_{e}\left(T_{R \Omega}-h / 2\right)
$$


where $h$ is the sampling period.

The coefficient $K_{\mathrm{c}}$ is used to assure stability, according to the demonstration from [25]. A nonlinear correction is made to move the characteristics $d M_{d}=f\left(x_{t 1} ; d e\right)$, from Figure $5 \mathrm{c}$, from the non-intervention area from the $\mathrm{x}$ axis, were $d M_{\mathrm{d}}$ has zero values for $e$ and $d e$ different from zero, in stability sector.

\subsection{Look-Up Table Implementation of the Fuzzy Block}

The solution for implementing the fuzzy blocks that gives the highest response speed, both in simulation and in practical applications, is the tabular implementation of the fuzzy block, in the form of a matrix, stored in the memory of the numerical control equipment. The models of the AC machine speed control structures are relatively complex, which makes the duration of a calculation step relatively long. The use of a pulse width modulation in the calculations resulted in a large number of iterations. The introduction of the fuzzy block in the simulation scheme in the form of the structure that requires the performance of fuzzification, inference, and defuzzification operations at each integration step, makes the calculation time increase even more. It is recalled that the inference method and the defuzzification method used are time consuming. The same fuzzy block computation problems arise when the practical implementation of fuzzy control on a physical control system of $\mathrm{AC}$ machines is required, at which an adequate real-time response speed must be ensured. The fuzzy block BF is represented by a nonlinear function of two variables $d M_{\mathrm{d}}=f_{\mathrm{BF}}(e, d e)$. This function is implemented tabularly, in the form of a matrix $D M_{\mathrm{d}}$ of elements $d M_{\mathrm{d}}\left(a_{\mathrm{e}}, a_{\mathrm{de}}\right)$, stored in the computer's memory. Such a 'fuzzy memory' has a data output $d M_{\mathrm{d}}$ and two address inputs $a_{\mathrm{e}}$ and $a_{\mathrm{de}}$. At the output, the memory shows the real value $d M_{\mathrm{d}}$ stored at the address $\left(a_{\mathrm{e}}, a_{\mathrm{de}}.\right)$. Addresses have integer values. In order to create the matrix, the discourse universes of the input quantities of the fuzzy block $e$ and $d e$ are discretized in $n_{\mathrm{c}}$ parts. By tabulating the function $d M_{\mathrm{d}}=f_{\mathrm{BF}}(e, d e)$ for all combinations of input values, we obtain $\left(n_{\mathrm{c}}+1\right)^{2}$ values for the output $d M_{\mathrm{dk}}=f_{\mathrm{R}}\left(e_{\mathrm{ae}}, d e_{\text {ade }}\right)$, where $a_{\mathrm{e}}$ $=1, \ldots, n_{\mathrm{c}}+1$ and $a_{\mathrm{de}}=1, \ldots, n_{\mathrm{c}}+1$. These values are stored in the matrix $D M_{\mathrm{d}}=\left[d i_{\mathrm{d}}\left(a_{\mathrm{e}}\right.\right.$, $\left.a_{\mathrm{de}}\right)$ ]. This array memory must be addressed with values $a_{\mathrm{e}}$ and $a_{\mathrm{de}}$. For the quantity $e$, a translation is made from $\left[-e_{\mathrm{M}}, e_{\mathrm{M}}\right]$ to $\left[1, n_{\mathrm{C}}+1\right]$, and for the quantity $d e$, a translation is made from $\left[-d e_{\mathrm{M}}, d e_{\mathrm{M}}\right]$ to $\left[1, n_{\mathrm{c}}+1\right]$. Memory addresses are integers, so to determine them, the integer part of $e_{\mathrm{t}}$ and $d e_{\mathrm{t}}$ must be calculated:

$$
\begin{gathered}
e_{t}=\frac{n_{c}}{2 e_{M}} e+\frac{n_{c}+2}{2}, d e_{t}=\frac{n_{c}}{2 d e_{M}} d e+\frac{n_{c}+2}{2}, \\
a_{e}=\left[e_{t}\right], a_{d e}=\left[d e_{t}\right]
\end{gathered}
$$

The function of the fuzzy block BF is implemented with an approximation of it:

$$
d M_{d}=f_{B F}(e, d e) \cong d M_{d}\left(a_{e}, a_{d e}\right)=f_{B F}^{*}\left(\left[e_{t}\right],\left[d e_{t}\right]\right)
$$

In the simulation, an implementation of fuzzy memory was chosen for an analog-todigital converter of only eight bits, a situation that is the most unfavorable case. Figure 6 shows the multi-input-single-output (MISO) transfer surface of the fuzzy block for the asynchronous machine. It was obtained by tabulating the function $f_{\mathrm{BF}}(e, d e)$ with a resolution of $1 / 2^{8}$ of the universes of discourse of the inputs.

The required memory decreases significantly. The number of samples for each speech universe becomes $2^{8}+1=257$. The number of memory locations required is 66.049 . The required memory capacity is almost $265 \mathrm{~KB}$. Such fuzzy memory can be stored in RAM during calculations. The simulations showed that even in this unfavorable case, good values of the quality indicators of the regulation can be obtained. 


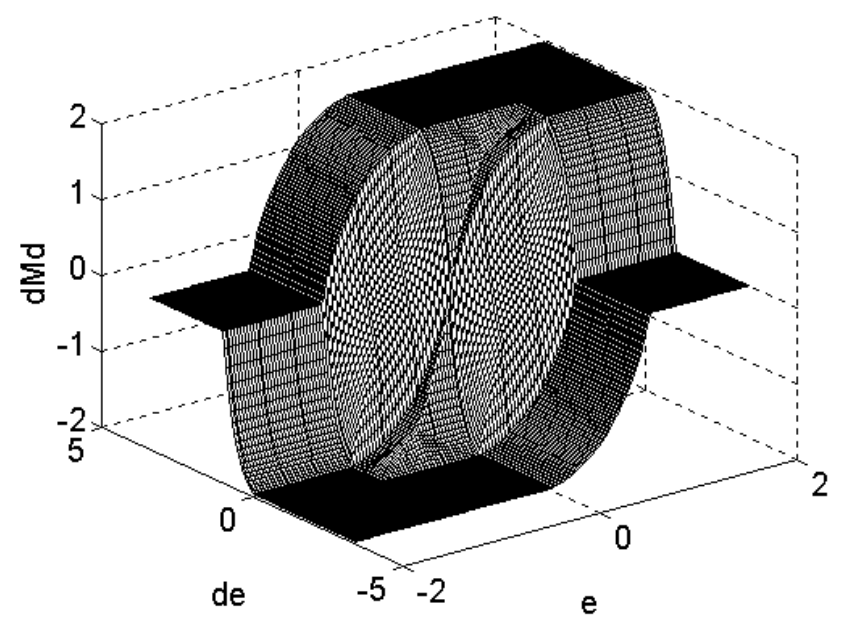

Figure 6. MISO transfer characteristic $d M_{\mathrm{d}}=f_{\mathrm{BF}}(e, d e)$ of the fuzzy block implemented as a look-up table.

3. Results

3.1. Transient Features

3.1.1. Simulation Conditions

The analysis of the behavior of the regulation systems was done in some cases, as specified below. The abbreviated specification of the analysis cases was made according to the symbols in Figure 7.

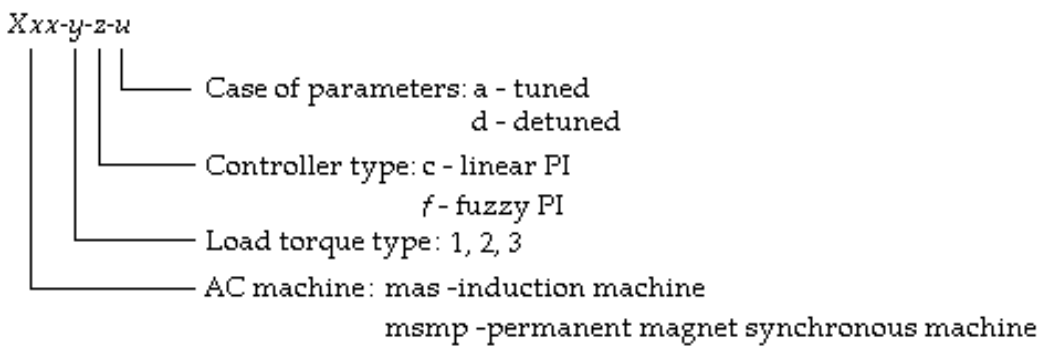

Figure 7. The meanings from the notation of the analysis cases.

It was chosen to analyze the behavior to the modification of the parameters in time, due to the temperature, the magnetic saturation, or the modification of the load and the case of deviations when estimating the machine parameters. The values of the parameters taken in the analysis for the case of induction machine (mas) are presented in Table 1 and for the case of the permanent magnet synchronous machine ( $m s m p)$ in Table 2 for the tuned case $(a)$ and for the detuned case $(d)$.

Table 1. The values of the parameters taken in the analysis for the induction machine (mas).

\begin{tabular}{ccccccc}
\hline & $R_{\mathrm{r}}[\Omega]$ & \multicolumn{2}{c}{$J\left[\mathrm{kgm}^{2}\right]$} & \multicolumn{2}{c}{$k_{\mathrm{f}}[\mathrm{Nms}]$} \\
\hline$a$ & $d$ & $a$ & $d$ & $a$ & $d$ \\
\hline 12.4 & 24.8 & 0.01 & 0.02 & 0.0008 & 0.0016 \\
\hline
\end{tabular}

Table 2. The values of the parameters taken in the analysis for the permanent magnet synchronous machine (msmp).

\begin{tabular}{ccccccc}
\hline & $R_{\mathrm{r}}[\Omega]$ & \multicolumn{2}{c}{$J\left[\mathrm{kgm}^{2}\right]$} & \multicolumn{2}{c}{$k_{\mathrm{f}}[\mathrm{Nms}]$} \\
\hline$a$ & $d$ & $a$ & $d$ & $a$ & $d$ \\
\hline 0.6 & 1.2 & 0.001 & 0.002 & 0.0001 & 0.0002 \\
\hline
\end{tabular}


The results obtained using the fuzzy PI speed controller, denoted with $(f)$, were compared with the results obtained in the conventional control case, denoted with (c) when using a linear PI speed control. The linear regulator was designed using the symmetry criterion in Kessler's version [32], which is a currently recommended method in practice. In the case of conventional control, a smoothing element located at the prescription input of the control system is also used, which is commonly in practice [29,32].

Three types $(1,2,3)$ of load torques $M_{s}$ were considered [29]. Their mechanical characteristics are represented in Figure $8 \mathrm{a}-\mathrm{c}$, respectively.

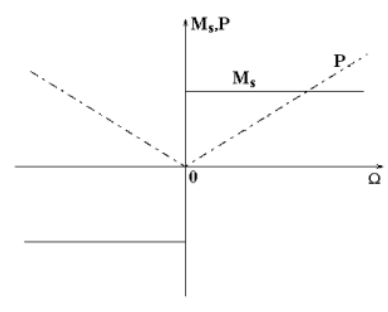

(a)

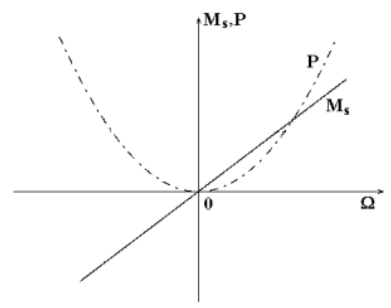

(b)

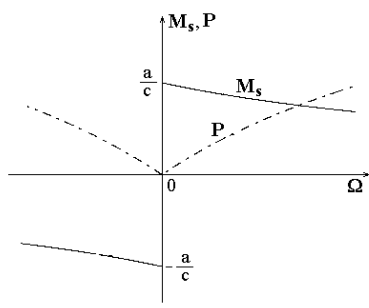

(c)

Figure 8. The mechanical characteristics of the torques (a) type 1, (b) type 2, (c) type 3.

In the simulation scenario with load torque 1 , it was considered to start the drive unloaded, then load it with a nominal torque and then reverse it. In the simulation scenarios with load torques 2 and 3, it was considered to start the drive in nominal load and then to reverse it.

\subsubsection{Induction Motor Characteristics}

The transient state characteristics of the torque $M$ and angular velocity $\Omega$, in cases mas-1(2,3)-f- $a(d)$, are presented in Figure 9.
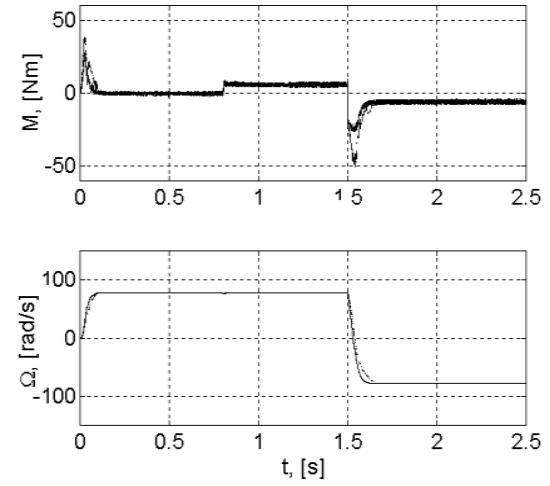

(a)
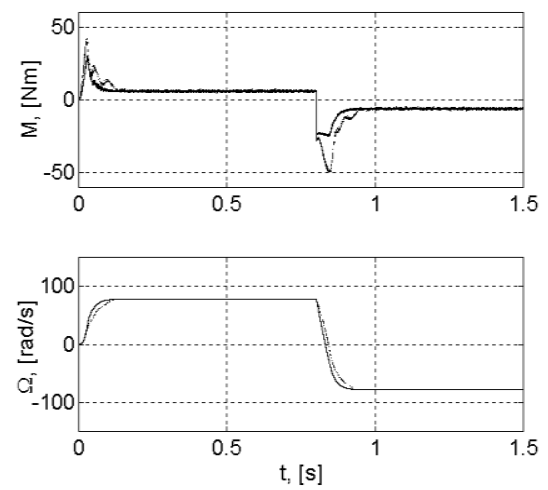

(b)
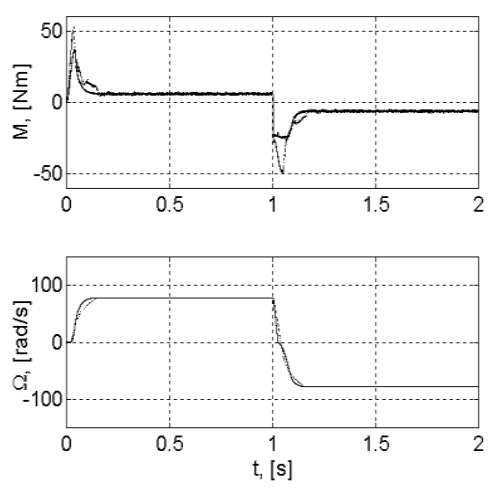

(c)

Figure 9. Electromagnetic torque $M$ and angular velocity $\Omega$, in cases: (a) mas-1-f-a(d), (b) mas-2-f-a(d), (c) mas-2-f-a(d), $a$-solid line, $d$-dashed line.

For detuned parameters, the torque is greater in the transient region and the rise time is longer. The overshoot at the start and at reverse is zero. In the transient state, the machine is driven with the maximum torque. Therefore, the acceleration is maximum and the speed variation has a maximum slope.

The transient state characteristics of the angular velocity $\Omega$, in cases mas-1(2,3)- $f(c)-a(d)$ are presented in Figure 10. 


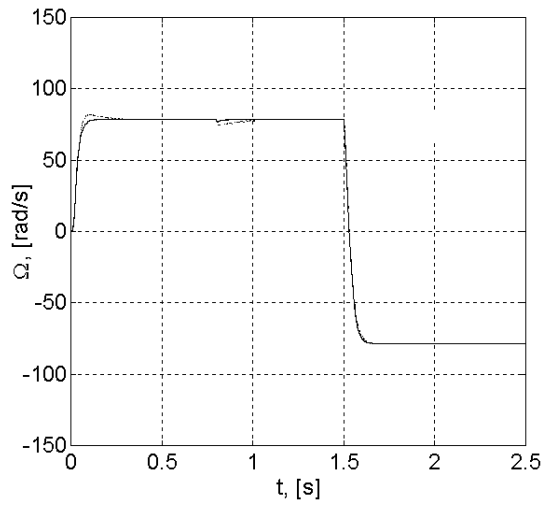

(a)

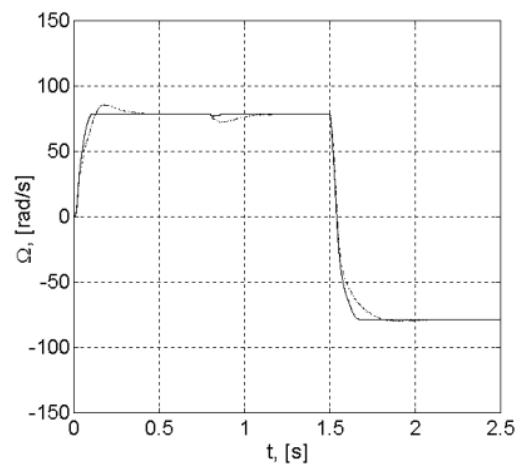

(d)

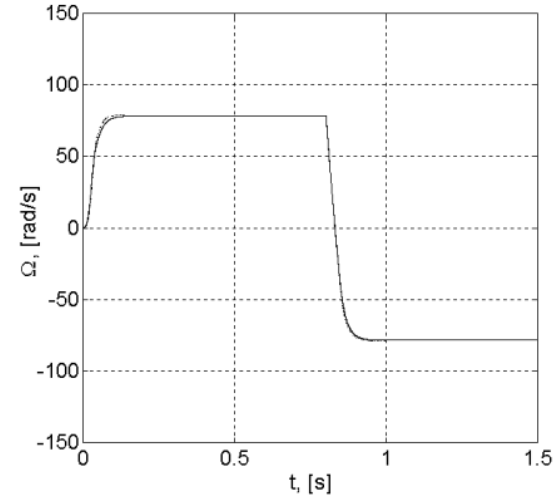

(b)

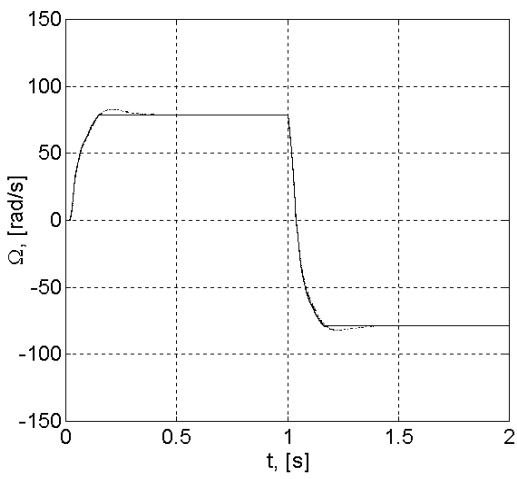

(e)

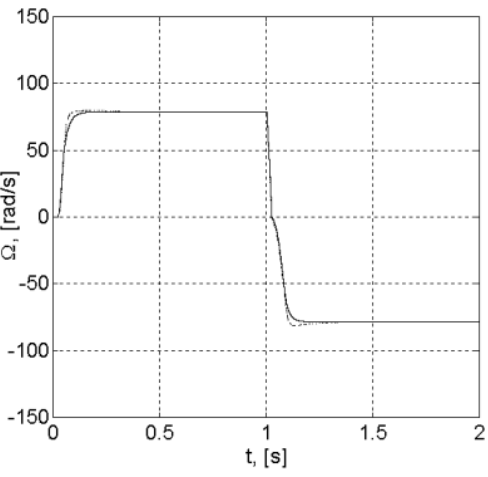

(c)

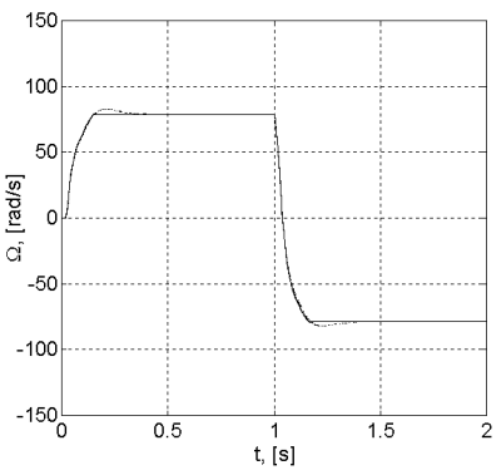

(f)

Figure 10. Angular velocity $\Omega$, in cases (a) mas-1-f(c)-a, (b) mas-2-f(c)-a, (c) mas-3-f(c)-a, (d) mas-1-f(c)-d, (e) mas-2-f(c)-d, (f) mas-3-f(c)-d,f-solid line, $c$ - dashed line.

The values of the performance criteria indicators are presented in Table 3 and they are discussed in Section 4.

Table 3. Performance indicator values for the induction machine.

\begin{tabular}{|c|c|c|c|c|c|c|c|c|c|c|c|}
\hline $\begin{array}{l}\text { Analysis } \\
\text { Case }\end{array}$ & $\begin{array}{c}\sigma_{1} \\
{[\%]}\end{array}$ & $\begin{array}{c}t_{\mathrm{r} \Omega} \\
{[\mathrm{s}]}\end{array}$ & $\begin{array}{l}\sigma_{1 \mathrm{M}} \\
{[\%]}\end{array}$ & $\begin{array}{c}t_{\mathrm{cM}} \\
{[\mathrm{s}]}\end{array}$ & $\begin{array}{l}\sigma_{1 \mathrm{r}} \\
{[\%]}\end{array}$ & $\begin{array}{l}t_{\mathrm{rr}} \\
{[\mathrm{s}]}\end{array}$ & $\begin{array}{c}E \\
.10^{-5}\end{array}$ & $\begin{array}{l}\Delta \sigma_{1} \\
{[\%]}\end{array}$ & $\begin{array}{c}\Delta \sigma_{1 \mathrm{M}} \\
{[\%]}\end{array}$ & $\begin{array}{c}\Delta t_{\mathrm{r} \Omega} \\
{[\mathrm{s}]}\end{array}$ & $\begin{array}{c}\Delta t_{\mathrm{cM}} \\
{[\mathrm{s}]}\end{array}$ \\
\hline Mas-1-c-a & 4.5 & 0.19 & 5.7 & 0.15 & 2.0 & 0.13 & 720 & \multirow{2}{*}{4.5} & \multirow{2}{*}{3.1} & \multirow{2}{*}{0.1} & \multirow{2}{*}{0.14} \\
\hline Mas-1-f-a & 0 & 0.09 & 2.6 & 0.01 & 0 & 0.12 & 679 & & & & \\
\hline Mas-1-c-d & 9.6 & 0.34 & 8.3 & 0.25 & 3.2 & 0.45 & 1068 & \multirow{2}{*}{9.6} & \multirow{2}{*}{6.4} & \multirow{2}{*}{0.25} & \multirow{2}{*}{0.23} \\
\hline Mas-1-f-d & 0 & 0.09 & 1.9 & 0.02 & 0 & 0.15 & 909 & & & & \\
\hline Mas-2-c-a & 0.6 & 0.09 & - & - & 0.6 & 0.16 & 701 & \multirow{2}{*}{0.6} & \multirow[t]{2}{*}{ - } & \multirow{2}{*}{0.01} & \multirow[t]{2}{*}{ - } \\
\hline Mas-2-f-a & 0 & 0.1 & - & - & 0 & 0.12 & 703 & & & & \\
\hline Mas-2-c-d & 4.4 & 0.12 & - & - & 3.2 & 0.23 & 954 & \multirow{2}{*}{4.0} & \multirow{2}{*}{-} & \multirow{2}{*}{0} & \multirow{2}{*}{-} \\
\hline Mas-2-f-d & 0.4 & 0.12 & - & - & 0 & 0.13 & 937 & & & & \\
\hline Mas-3-c-a & 1.9 & 0.19 & - & - & 3.8 & 0.22 & 863 & \multirow{2}{*}{1.9} & \multirow{2}{*}{ - } & \multirow{2}{*}{0.08} & \multirow{2}{*}{-} \\
\hline Mas-3-f-a & 0 & 0.11 & - & - & 0 & 0.14 & 896 & & & & \\
\hline Mas-3-c-d & 4.5 & 0.32 & - & - & 5.1 & 0.33 & 1021 & \multirow{2}{*}{3.5} & \multirow{2}{*}{ - } & \multirow{2}{*}{0.2} & \multirow[t]{2}{*}{ - } \\
\hline Mas-3-f-d & 1.0 & 0.12 & - & - & 1.3 & 0.16 & 1011 & & & & \\
\hline
\end{tabular}

\subsubsection{Permanent Magnet Synchronous Motor Characteristics}

The transient state characteristics of torque $M$ and angular velocity $\Omega$, in cases $m s m p$ 1(2,3)-f-a(d), are presented in Figure 11. 

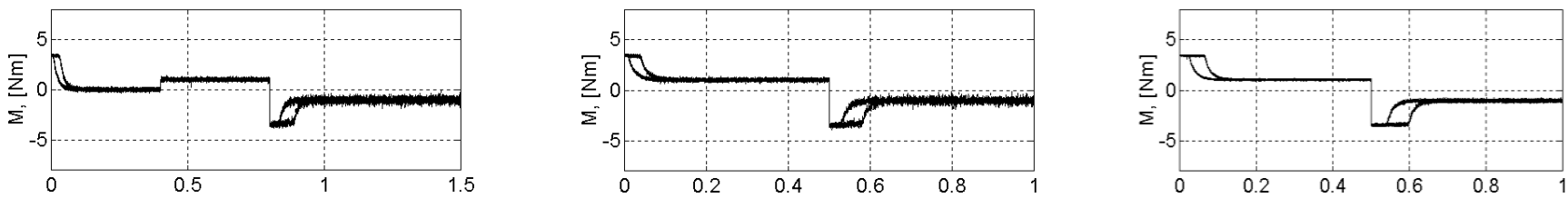

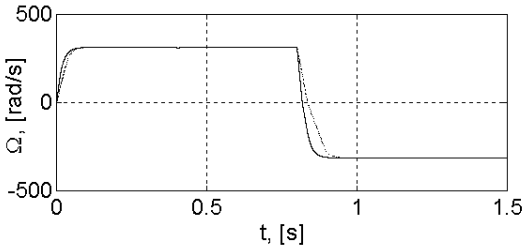

(a)

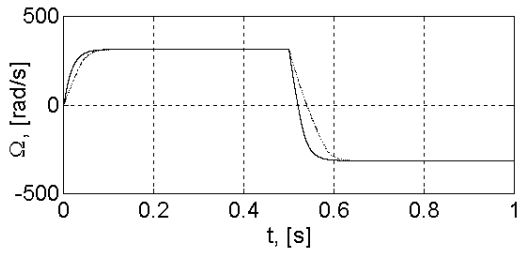

(b)

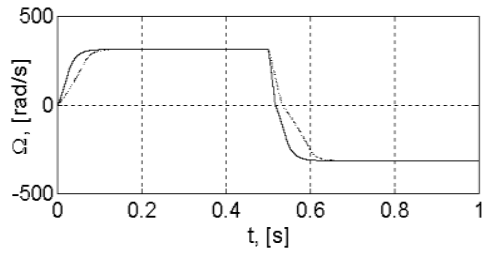

(c)

Figure 11. Electromagnetic torque $M$ and angular velocity $\Omega$, in cases (a) masmp-1-f-a(d), (b) $m s m p-2-f-a(d),(\mathbf{c}) m s m p-2-f-a(d)$, $a$-solid line, $d$-dashed line.

The transient state characteristics of the angular velocity $\Omega$, in cases $m s m p-1(2,3)-f(c)$ $a(d)$, are presented in Figure 12 .

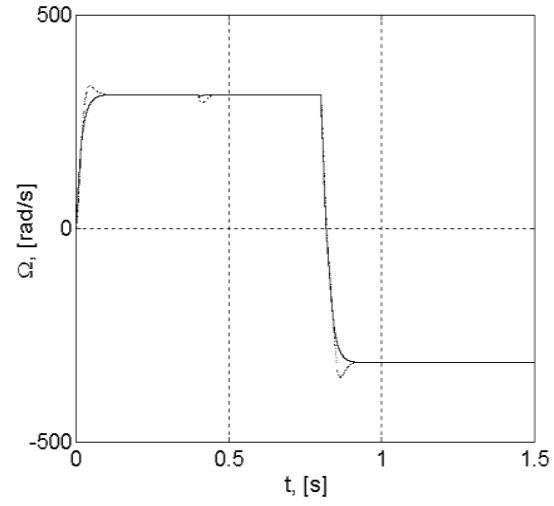

(a)

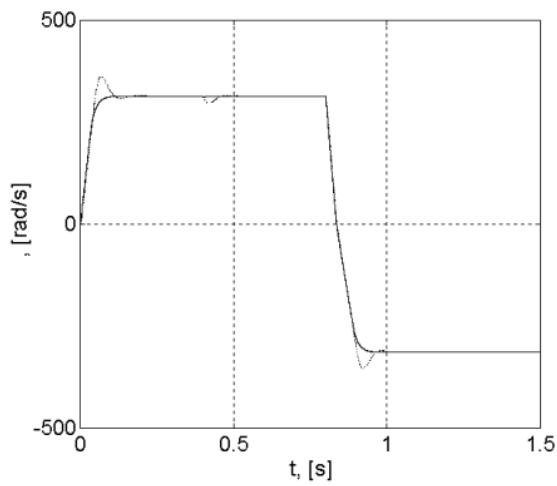

(d)

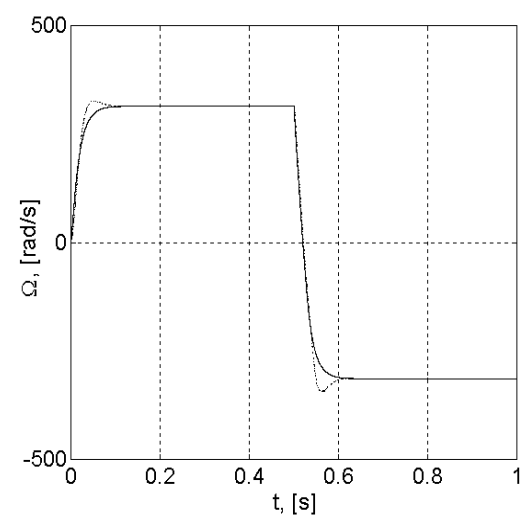

(b)

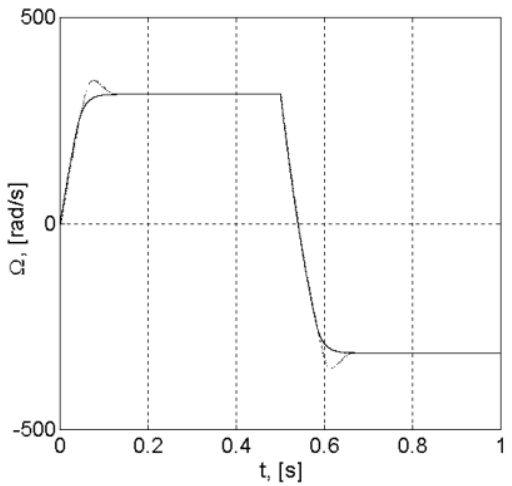

(e)

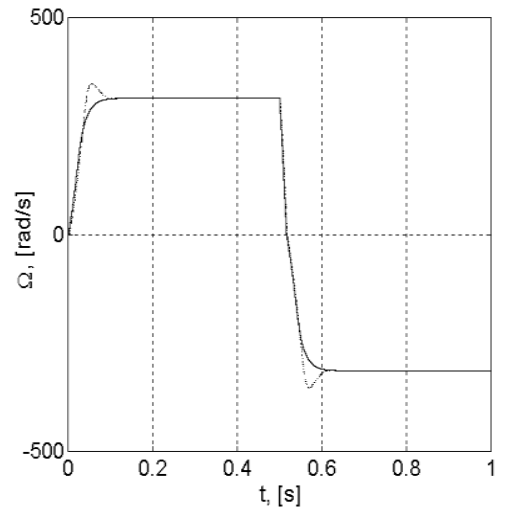

(c)

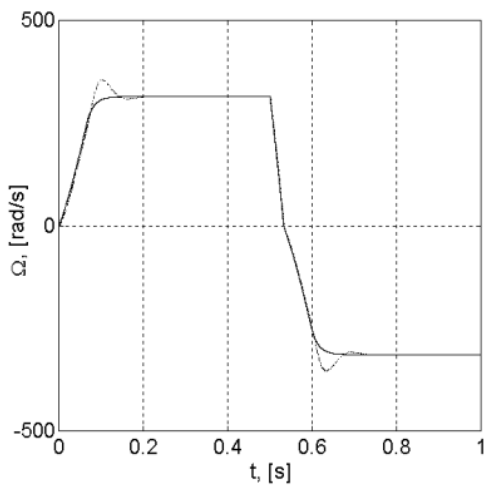

(f)

Figure 12. Angular velocity $\Omega$, in cases (a) $m s m p-1-f(c)-a$, (b) $m s m p-2-f(c)-a$, (c) $m s m p-3-f(c)-a$, (d) $m s m p-1-f(c)-d$, (e) $m s m p-2-$ $f(c)-d$, (f) $m s m p-3-f(c)-d, f$-solid line, $c$-dashed line.

The values of the performance criteria indicators are presented in Table 4 and they are discussed in Section 4. 
Table 4. Performance indicator values for the synchronous machine.

\begin{tabular}{|c|c|c|c|c|c|c|c|c|c|c|c|}
\hline $\begin{array}{l}\text { Analysis } \\
\text { Case }\end{array}$ & $\begin{array}{c}\sigma_{1} \\
{[\%]}\end{array}$ & $\begin{array}{c}t_{\mathrm{r} \Omega} \\
{[\mathrm{s}]}\end{array}$ & $\begin{array}{l}\sigma_{1 \mathrm{M}} \\
{[\%]}\end{array}$ & $\begin{array}{l}t_{\mathrm{cM}} \\
{[\mathrm{s}]}\end{array}$ & $\begin{array}{l}\sigma_{1 \mathrm{r}} \\
{[\%]}\end{array}$ & $\begin{array}{l}t_{\mathrm{rr}} \\
{[\mathrm{s}]}\end{array}$ & $\begin{array}{c}E \\
.10^{-5}\end{array}$ & $\begin{array}{l}\Delta \sigma_{1} \\
{[\%]}\end{array}$ & $\begin{array}{c}\Delta \sigma_{1 \mathrm{M}} \\
{[\%]}\end{array}$ & $\begin{array}{c}\Delta t_{\mathrm{r} \Omega} \\
{[\mathrm{s}]}\end{array}$ & $\begin{array}{c}\Delta t_{\mathrm{cM}} \\
{[\mathrm{s}]}\end{array}$ \\
\hline Msmp-1-c-a & 6.7 & 0.07 & 6.4 & 0.04 & 11.4 & 0.09 & 6.81 & \multirow{2}{*}{6.7} & \multirow{2}{*}{5.1} & \multirow{2}{*}{0.01} & \multirow{2}{*}{0.04} \\
\hline Msmp-1-f-a & 0 & 0.06 & 1.3 & 0 & 0 & 0.08 & 6.17 & & & & \\
\hline Msmp-1-c-d & 16.2 & 0.13 & 5.4 & 0.04 & 13.1 & 0.16 & 12.65 & \multirow{2}{*}{16.2} & \multirow{2}{*}{4.8} & \multirow{2}{*}{0.05} & \multirow{2}{*}{0.04} \\
\hline Msmp-1-f-d & 0 & 0.08 & 0.6 & 0 & 0 & 0.13 & 11.96 & & & & \\
\hline Msmp-2-c-d & 4.5 & 0.07 & - & - & 9.9 & 0.09 & 7.02 & \multirow{2}{*}{4.5} & \multirow{2}{*}{-} & \multirow{2}{*}{0} & \multirow[t]{2}{*}{-} \\
\hline Msmp-2-f-d & 0 & 0.07 & - & - & 0 & 0.08 & 6.37 & & & & \\
\hline Msmp-2-c-a & 10.8 & 0.12 & - & - & 11.8 & 0.15 & 13.05 & \multirow{2}{*}{10.8} & \multirow{2}{*}{-} & \multirow{2}{*}{0.04} & \multirow{2}{*}{-} \\
\hline Msmp-2-f-d & 0 & 0.08 & - & - & 0 & 0.12 & 12.29 & & & & \\
\hline Msmp-3-c-a & 10.8 & 0.08 & - & - & 13.1 & 0.1 & 7.76 & \multirow{2}{*}{10.8} & \multirow{2}{*}{-} & \multirow{2}{*}{0} & \multirow[t]{2}{*}{-} \\
\hline Msmp-3-f-d & 0 & 0.08 & - & - & 0 & 0.1 & 6.99 & & & & \\
\hline Msmp-3-c-a & 13.1 & 0.16 & - & - & 13.1 & 0.17 & 14.50 & \multirow{2}{*}{13.1} & \multirow[t]{2}{*}{ - } & \multirow{2}{*}{0.03} & \multirow[t]{2}{*}{-} \\
\hline Msmp-3-f-d & 0 & 0.13 & - & - & 0 & 0.13 & 13.63 & & & & \\
\hline
\end{tabular}

\subsection{Performance Indicators}

The values of the performance indicators for the induction machine control system are presented in Table 3, and the values for the synchronous machine control system are presented in Table 4 . They are obtained from the above characteristics.

The meanings of the notations in the tables are: $\sigma_{1}$-speed overshoot at start-up; $t_{\mathrm{r} \Omega}$ rising time; $\sigma_{1 \mathrm{M}}$-the maximum deviation of the speed from the effect of the disturbing load torque; $t_{\mathrm{cM}}$-time to eliminate the effect of disturbance; $\sigma_{1 \mathrm{r}}$-speed overshoot at reversal; $t_{\mathrm{rr}}$-reversal rise time; E-integral criterion; $\Delta \sigma_{1}$-overshoot difference between overshoot at nominal parameters and overshoot at detuned parameters; $\Delta \sigma_{1 \mathrm{M}}-$ maximum deviation difference; $\Delta t_{\mathrm{r} \Omega}$-rise time difference; $\Delta t_{\mathrm{cM}}$ - difference of torque effect elimination time. The error integral criterion has relation (13). It is integral to the square of the speed error.

$$
E=\int\left(\Omega^{*}-\Omega\right)^{2} d t
$$

\subsection{Some Results from a Digital Implementation}

In [20], the author presented an example of the implementation of a speed control system of a brushless motor with a Hall sensor encoder, based on a TMS320LF2407 DSP platform. The structure of the equipment is presented in Figure 13a.

The test platform is using a Texas Instruments motion control kit MSK 2407, monitor software, and development software installed on a personal computer (PC), a power electronic converter PM-50 with a three phase inverter and auxiliary circuits, with structures from Figure 13a. The implementation of the fuzzy block BF may be done using a lookup table, as presented in Section 2.4. This is the way that assures the minimum time response in the practical implementation of a fuzzy block. Using the fuzzy PI controller, the characteristics in Figure 13b may be obtained. This was compared with the characteristic for a linear PI speed controller. This example demonstrates that using fuzzy PI controllers may improve some performance indicators, obtaining a shorter rise time and a zero overshoot. 


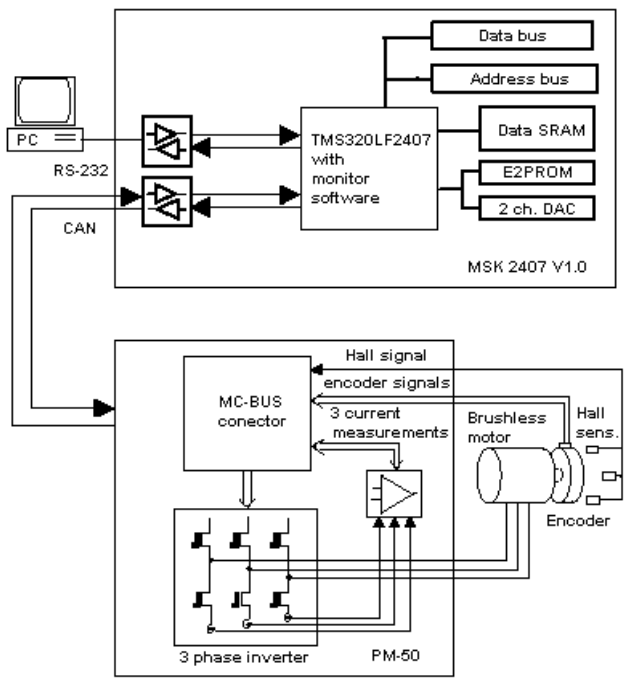

(a)

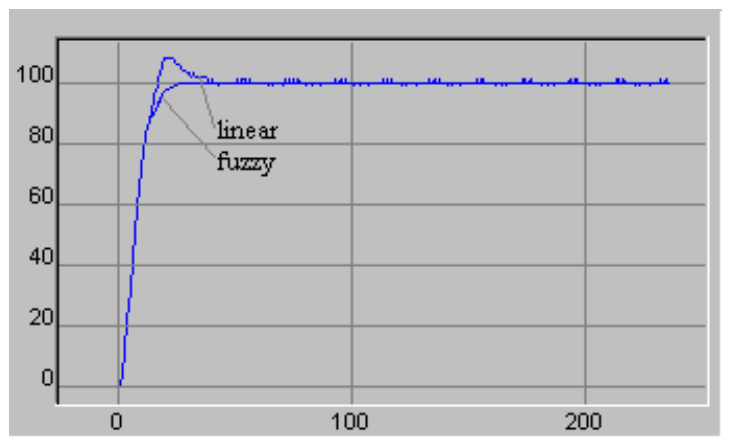

(b)

Figure 13. (a) Equipment structure for practical experimentation. (b) Speed characteristics on the graphic interface.

\subsection{Example of Calculating the Reduction of Energy Consumed}

Using the results obtained by simulation, from the transient state characteristics of torque and speed and the values of the performance indicators in the tables, a simple calculation of the energy difference $\Delta W$ between the energy consumed in linear regulation and the energy consumed in fuzzy regulation in transient states can be made. An empiric formula may be used:

$$
\Delta W \cong\left(M_{c} \Omega_{\mathrm{c}} \mathrm{t}_{\mathrm{rc}}-M_{f} \Omega_{\mathrm{f}} \mathrm{t}_{\mathrm{rf}}\right) \cong\left(1 \cdot 05 \cdot M_{n} \cdot 1 \cdot 05 \cdot \Omega_{\mathrm{n}} \mathrm{t}_{\mathrm{r}}-M_{n} \Omega_{\mathrm{n}} \mathrm{t}_{\mathrm{r}}\right) \cong 0.1 \cdot \mathrm{P}_{\mathrm{n}} \mathrm{t}_{\mathrm{r}}
$$

were $M$ is the torque; $\Omega$ is the speed; and $t$ is the duration of transient regime for the linear, or conventional case denoted with $c$ and for fuzzy case denoted with $f$. The case of nominal speed control, denoted with $n$, was chosen. The duration of the longer transitional regime was chosen from the conventional case $t_{\mathrm{r}}$. Based on the characteristics and table values, for the case of conventional regulation, it is approximated that the torque and the rotation speed were $5 \%$ higher than in the case of fuzzy regulation. Thus, it can be said that the energy difference was about 0.1 of the nominal energy consumed during the transient state.

\section{Discussion}

From the characteristics of the transient regime and from the values from the tables presented above, the following can be observed. Fuzzy logic-based control provides zero overshoot $\sigma_{1}$, unlike conventional control, which provides a greater overshoot, both in the case of tuned parameters and in the case of detuned parameters, for all three load torques. The rise time $t_{\mathrm{r} \Omega}$ was smaller in all cases with fuzzy control. The effect of disturbing load torque was eliminated faster in the case of fuzzy control: $t_{\mathrm{cM}}$ and $\sigma_{1 \mathrm{M}}$ were smaller. The reversal time $t_{\text {rr }}$ was shorter for fuzzy control. The error integral criterium had smaller values for fuzzy control. The values of all quality indicators were better in the case of fuzzy control, in all cases analyzed. It should be noted that better values were obtained in the most unfavorable cases using bipositional current regulators and the implementation of fuzzy memory with the lowest resolution. The values of the torque developed by the machine in transient mode were lower in the case of fuzzy control than in the case of conventional control. The duration of the transitional regime was shorter. These aspects were valid in all cases analyzed, for different values of the parameters and for different load torques. The fact that at fuzzy control, the torque developed by the machine was lower, the speed overshoot was zero, and the duration of the transient state was shorter, 
leading to the conclusion that the consumed energy was smaller, which leads to energy saving.

\section{Conclusions}

The paper presents an analysis performed by the modeling and simulation of the behavior of the speed control structures with a fuzzy PI controller of the asynchronous machine vector controlled with indirect orientation after the rotor flux and the speed control structure with a fuzzy PI controller of the permanent magnet synchronous machine vector controlled with orientation after the rotor flux. The analyses were performed for nominal values of the machine parameters and for deviated values of the parameters by $100 \%$. Additionally, three different types of load torques commonly encountered in practice were considered. The paper shows the design of the fuzzy regulators used. The fuzzy blocks were implemented in the tabular manner, as matrix stored in memory, the solution that gives the highest response speed.

The values obtained for fuzzy regulation were compared with the values obtained for conventional regulation with linear PI speed regulators. Linear PI regulators are the most common and widely used in commercial electric drives.

This paper demonstrates that the use of fuzzy PI regulators for regulating the speed of AC electric motors leads to a reduction in energy consumed in transient states and an improvement in the quality indicators of regulation. The paper also demonstrates that control systems based on fuzzy logic are more robust to errors in identifying the parameters of electric machines. They are also more robust to the effect of disturbing load torque.

Funding: This research received no external funding.

Institutional Review Board Statement: Ethical review and approval were waived for this study, due to reason as follows. The research does not involve human subjects, the use of animals in research, cell lines, plants, clinical trials, sex or gender notions and there is no potential dispute on borders and territories.

Informed Consent Statement: Patient consent was waived due to the reason no other subjects were involved in the study.

Data Availability Statement: Data is contained within the article.

Conflicts of Interest: The author declare no conflict of interest.

\section{References}

1. De Luca, F.; Calderaro, V.; Galdi, V. A Fuzzy Logic-Based Control Algorithm for the Recharge/V2G of a Nine-Phase Integrated On-Board Battery Charger. Electronics 2020, 9, 946. [CrossRef]

2. Štil, V.J.; Varga, T.; Benšić, T.; Barukčić, M. A Survey of Fuzzy Algorithms Used in Multi-Motor Systems Control. Electronics 2020, 9, 1788. [CrossRef]

3. Zhang, W.; Fang, Y.; Ye, R.; Wang, Z. Analysis and Design of a Double Fuzzy PI Controller of a Voltage Outer Loop in a Reversible Three-Phase PWM Converter. Energies 2020, 13, 3778. [CrossRef]

4. Pérez-Pimentel, Y.; Osuna-Galán, I.; Avilés-Cruz, C.; Villegas-Cortez, J. Power Supply Management for an Electric Vehicle Using Fuzzy Logic. Appl. Comput. Intell. Soft Comput. 2018, 2846748. [CrossRef]

5. Al-Jazaeri, A.O.; Samaranayake, L.; Longo, S.; Auger, S.D. Fuzzy Logic Control for Energy Saving in Autonomous Electric Vehicles. In Proceedings of the 2014 IEEE International Electric Vehicle Conference (IEVC), Florence, Italy, 17-19 December 2014.

6. Joshi, G.; Pinto Pius, A.J. Type-1 Mamdani Fuzzy Logic Controller for Electric Vehicle Drive. In Proceedings of the 2019 International Conference on Smart Systems and Inventive Technology ICSSIT, Tirunelveli, India, 27-29 November 2019.

7. Acikgoz, H. Real-time adaptive speed control of vector-controlled induction motor drive based on online-trained Type-2 Fuzzy Neural Network Controller. Int. Trans. Electr. Energy Syst. 2020, 30, e12678. [CrossRef]

8. Hannan, M.A.; Abd, J.; Ali Hossain Lipu, M.S.; Mohamed, A.; Jern Ker, P.; Indra Mahlia, T.M.; Mansor, M.; Hussain, A.; Muttaqi, K.M.; Dong, Z.Y. Role of optimization algorithms based fuzzy controller in achieving induction motor performance enhancement. Nat. Commun. 2020, 11, 3792. [CrossRef]

9. Venu Gopal, B.T.; Shivakumar, E.G.; Ramesh, H.R. An Experimental Setup for Implementation of Fuzzy Logic Control for Indirect Vector-Controlled Induction Motor Drive. In Advances in Control Instrumentation Systems; Lecture Notes in Electrical Engineering book series; Springer: Singapore, 2020; Volume 660, pp. 193-203. 
10. Bose, B.K. Expert System, Fuzzy Logic and Neural Network Applications in Power Electronics and Motion Control. Proc. IEEE 1994, 8, 1303-1323. [CrossRef]

11. Bolognani, S.; Zigliotto, M. Fuzzy Logic Control of a Switched Reluctance Motor Drive. In Proceedings of the Conference Record of the 1993 IEEE Industry Applications Conference Twenty-Eighth IAS Annual Meeting, Toronto, ON, Canada, 2-8 October 1993.

12. Cerruto, E.; Consoli, A.; Raciti, A.; Testa, A. Fuzzy Adaptive Vector Control of Induction Motor Drives. IEEE Trans. Power Electron. 1997, 6, 1028-1040. [CrossRef]

13. Slemon, G.R. Electrical Machines for Variable-Frequency Drives. Proc. IEEE 1994, 8, 1123-1139. [CrossRef]

14. Lorenz, R.D.; Lipo, T.A.; Novotny, D.W. Motion Control with Induction Motors. Proc. IEEE 1994, 8, 1215-1240. [CrossRef]

15. Jahnd, T.M. Motion Control with Permanent Magnet AC Mashines. Proc. IEEE 1994, 8, 1241-1252.

16. Holtz, J. Pulse Width Modulation for Electronic Power Conversion. Proc. IEEE 1994, 8, 1194-1214. [CrossRef]

17. Mohan, N.; Robbins, W.P.; Underland, T.M.; Nilsen, R.; Mo, O. Simulation of Power Electronic and Motion Control Systems-An Overview. Proc. IEEE 1994, 8, 1287-1302. [CrossRef]

18. Buhler, H. Reglage Par Logique Floue; Press Polytechniques et Universitaires Romand: Lausane, Switzerland, 1994.

19. Volosencu, C. Fuzzy Control of Electrical Drives, based on Fuzzy Logic. WSEAS Trans. Syst. Control $2008,9,809-822$.

20. Volosencu, C. Speed Control of a Permanent Synchronous Motor, Based on a Quasi-Fuzzy Controller. In Proceedings of the 10th European Conference on Power Electronics and Applications, EPE, Toulouse, France, 2-4 September 2003.

21. Volosencu, C. Demonstration by Simulation of the Robustness of the Fuzzy Control System of a DC Motor at Errors at the Parameter Identification. In Proceedings of the Pemc'98 Conference, Prague, Czech Republic, 8-10 September 1998.

22. Volosencu, C. Tuning Fuzzy PID Controllers. In Theory, Tuning and Application to Frontier Areas; Rames, C.P., Ed.; IntechOpen: Rijeka, Croatia, 2012; pp. 171-190.

23. Volosencu, C. Pseudo-Equivalence of Fuzzy PI Controller. In Proceedings of the 8th WSEAS International Conference on Signal Processing, Robotics and Automation (ISPRA09), Cambridge, UK, 21-23 February 2009; pp. 162-168.

24. Volosencu, C. Pseudo-Equivalence of Fuzzy PID Controllers. WSEAS Trans. Syst. Control 2009, 4, 163-176.

25. Volosencu, C. Stabilization of Fuzzy Control Systems. WSEAS Trans. Syst. Control 2008, 10, 879-896.

26. Volosencu, C. Introductory Chapter: Basic Properties of Fuzzy Relations. In Fuzzy Logic; Volosencu, C., Ed.; IntechOpen: Rijeka, Croatia, 2020; pp. 3-10.

27. Volosencu, C. On Some Properties of Fuzzy Systems. In Proceedings of the 8th WSEAS International Conference on Signal Processing, Robotics and Automation (ISPRA09), Cambridge, UK, 21-23 February 2009; pp. 178-186.

28. Volosencu, C. Properties of Fuzzy Systems. WSEAS Trans. Syst. Control 2009, 2, 210-228.

29. Boldea, I.; Nasar, S.A. Vector Control of A.C. Drives; CRC Press: Boca Raton, FL, USA, 1992.

30. Leonhard, W. Control of Electrical Drives; Springer: Berlin, Germany, 1985.

31. De Doncker, R.K.; Novotny, D.W. The Universal Field Oriented Controller. IEEE Trans. Ind. Appl. 1994, 30, 1. [CrossRef]

32. Kessler, C. Das symmetrische optimum. Regelungstechnik 1958, 6, 395-400, 432-436. 